\title{
O Espaço Socioprofissional da Estratégia Saúde da Família sob a Perspectiva de Psicólogos
}

\author{
Léo Barbosa Nepomuceno \\ Universidade Federal do Ceará, CE, Brasil.
}

\author{
Ricardo José Soares Pontes \\ Universidade Federal do Ceará, CE, Brasil.
}

\begin{abstract}
Resumo: A Estratégia Saúde da Família (ESF) tem se constituído como porta de entrada para os psicólogos no Sistema Único de Saúde do Brasil, oportunizando acesso da população às práticas psicológicas e contribuindo para a expansão do espaço de atuação profissional. O presente trabalho tem como objetivos compreender o espaço socioprofissional da ESF, a partir da ótica de psicólogos inseridos no campo, e analisar os lugares ocupados pelas práticas da Psicologia no referido contexto. Utiliza como referencial teórico o conceito de campo social em Pierre Bourdieu. Consiste em estudo hermenêutico, de abordagem qualitativa, em que foram entrevistados 18 psicólogos com experiência de atuação nos campos da atenção e formação. Os resultados apontam para a caracterização de um processo de construção social das práticas psicológicas no campo, marcado pela territorialização, o ineditismo das práticas e a articulação com outros serviços e saberes técnico-científicos. O campo é descrito como hierarquizado e conflituoso, destacando-se a hegemonia do modelo biomédico e as desigualdades de poder entre as profissões. O lugar das práticas psicológicas na ESF, por um lado, é apontado como subalterno frente à hegemonia médica, por outro, é prestigiado por sua especificidade em lidar com dimensões subjetivas do processo saúde-doença-cuidado.
\end{abstract}

Palavras-chave: Psicologia, Estratégia Saúde da Família, Sistema Único de Saúde, Prática Profissional.

\section{The Social-Professional Space of the Family Health Strategy from the Perspective of Psychologists}

\begin{abstract}
The Family Health Strategy (ESF) has been established as a gateway for psychologists in the Unified Health System in Brazil, providing opportunities for access of the population to psychological practices and contributing to the expansion of professional workspace. This paper aims to understand the socio-professional space of the ESF, from the perspective of psychologists inserted in the field, and to analyze the places occupied by psychology practices in that context. The concept of social field in Pierre Bourdieu was used as a theoretical framework. This is a hermeneutical study of qualitative approach, in which 18 psychologists with experience in the fields of attention and training were interviewed. The results show some featuring elements of the social construction process of psychological practices in the field, marked by the territorialization, the uniqueness of the practices, and the collaboration with other services and technical-scientific knowledges. The field is described as hierarchical and confrontational, especially associated with the hegemony of the biomedical model and the power differentials between the professions. The place of psychological practices in the ESF, on the one hand, is appointed as subaltern to the medical hegemony, and on the other, is recognized by its specificity in dealing with subjective dimensions of the health-disease-care process.
\end{abstract}

Keywords: Psychology, Family Health Strategy, Unified Health System, Professional Practice. 


\title{
El Espacio Social de la Estrategia Salud de la Familia bajo la Perspectiva de Psicólogos
}

\begin{abstract}
Resumen: La Estrategia de Salud de la Familia (ESF) se ha establecido como una puerta de entrada para los psicólogos en el Sistema Único de Salud en Brasil, proporcionando oportunidades para el acceso de la población a las prácticas psicológicas y contribuindo a la expansión del espacio de trabajo profesional. Este trabajo tiene como objetivos comprender los espacios socioprofesionales de la ESF, desde la perspectiva de los psicólogos insertados en el campo, y analizar los lugares ocupados por las prácticas de psicología en ese contexto. Se utiliza como marco teórico el concepto de campo social en Pierre Bourdieu. Este es un estudio hermenéutico de enfoque cualitativo, en el que fueron entrevistados 18 psicólogos con experiencia en los campos de la atención y la formación. Los resultados muestran elementos del proceso de construcción social de las prácticas psicológicas en el campo, marcadas por la territorialización, la originalidad de las prácticas y la articulación con otros servicios y conocimientos técnico-científicos. El campo es descrito como jerarquizado y lleno de conflictos, destacándose la hegemonía del modelo biomédico y la disparidad de poder entre las profesiones. El lugar de las prácticas psicológicas en la ESF, por un lado, es nombrado como inferior, frente a la hegemonía médica; por el otro, es valorado por su especificidad en el tratamiento de las dimensiones subjetivas del proceso de atención de salud y enfermedad.
\end{abstract}

Palabras clave: Psicología, Estrategia Salud Familiar, Sistema Único de Salud, Práctica Profesional.

\section{Introdução}

A Estratégia Saúde da Família (ESF) é uma política pública que expressa o movimento de ampliação da rede assistencial no Sistema Único de Saúde (SUS) do Brasil, através do fortalecimento da proposta da Atenção Primária à Saúde (APS). Nesse processo de ampliação dos serviços de APS, os Centros de Saúde da Família (CSF) vem se constituindo como espaços novos para o desenvolvimento de práticas profissionais. Especialmente a partir da criação dos Núcleos de Apoio à Saúde da Família (NASF), novas profissões da saúde passam a ganhar um campo de atuação profissional, no qual participam ativamente na construção de saberes e práticas, por meio de processos de troca interprofissionais permeados por relações de poder, luta e negociações. Para a Psicologia, a ESF tem se constituído como a principal porta de entrada para os psicólogos no SUS, oportunizando acesso da população às práticas psicológicas e contribuindo para a expansão do espaço de atuação profissional. Assim, a análise de experiências de trabalho de psicólogos na ESF possibilita a discussão de importantes questões para pensar a profissionalização e a formação de profissionais incluídos nos serviços de saúde do SUS. Nesse contexto, o presente trabalho tem como objetivos: 1) Compreender o espaço socioprofissional da ESF, a partir da ótica de psicólogos com experiência de atuação e formação no campo e 2) Analisar os lugares ocupados por psicólogos no cenário de produção das práticas profissionais nos serviços de saúde estudados. A ESF é aqui analisada a partir do conceito de “campo social” (Bourdieu, 2004, 2011, 2012), visando a discussão sobre as relações interprofissionais existentes nos cenários de atuação do psicólogo, destacando a perspectiva da análise das relações de poder que perpassam o fazer profissional.

Nas últimas décadas, a ESF se destaca no conjunto de mudanças que vem se efetivando no desenvolvimento das políticas públicas de saúde no Brasil. Nesse contexto, o surgimento, em 1994, do Programa Saúde da Família (PSF) representa uma forma de "responder a uma tendência mundial de redução de custos, de desmedicalização da medicina e humanização dos serviços" (Camargo-Borges, \& Cardoso, 2005, p. 27). Originada no PSF, a ESF vem se constituindo como uma política responsável por empreender uma reestruturação no modelo de atenção à saúde (Brasil, 1997; Camargo-Borges, \& Cardoso, 2005; Dimenstein, \& Macedo, 2012). A APS, enquanto modelo de atenção à saúde, está ligada à ideia de fortalecer o acesso 
e a capacidade de acolhimento do sistema de saúde, a partir da atenção longitudinal e da responsabilidade sanitária de serviços comunitários e públicos, organizados em torno de áreas delimitadas geograficamente (Andrade, Barreto, \& Bezerra, 2006). A ESF situa-se na perspectiva da APS, das políticas universais de saúde e é entendida como mecanismo de reorientação do sistema de saúde, sendo: porta de entrada, responsabilização institucional e sanitária no processo de cuidado com a saúde articulado a toda rede de serviços. Outros aspectos são fundamentais para entender a especificidade do desenvolvimento das práticas em saúde na ESF, como sua busca pela aproximação entre atenção à saúde e participação comunitária, bem como a incorporação de formas intersetoriais e comunitárias de atuação em meio a um contexto político de disputas entre modelos de proteção social universais ou focados em grupos populacionais em situação de pobreza.

Afirmando um movimento de valorização da APS do SUS, a Portaria $N^{\circ}$ 154, de março de 2008 (Brasil, 2008) institui a criação dos Núcleos de Apoio à Saúde da Família (NASF) com objetivo de ampliar a abrangência das ações da ESF, aumentando o leque de serviços aos usuários e o escopo das ações. As áreas estratégicas de ação dos NASF são: práticas integrativas e complementares; reabilitação; alimentação e nutrição; saúde mental; serviço social; saúde da criança; saúde da mulher; e assistência farmacêutica. Para cada área estratégica de atuação, se preconiza algumas opções de profissionais para apoiar as equipes dos CSF. A Psicologia, cuja prática profissional é objeto de estudos do presente trabalho, é uma das profissões mencionadas para a área de saúde mental, tendo em vista a enorme demanda de problemas relacionados a transtornos mentais (Brasil, 2008).

A priorização da ESF, no contexto das políticas de saúde brasileiras, tem colocado em pauta a formação dos profissionais de saúde e a produção acadêmica no campo da Saúde Coletiva e da Psicologia, em que agentes e instituições se veem às voltas com questões advindas dos contextos de prática atualmente abertos (Dimenstein, \& Macedo, 2012; Lancman, Gonçalves, Cordone, \& Barros, 2013; Macedo, \& Dimenstein, 2011; Pitombeira, Xavier, Barroso, \& Oliveira, 2016; Spink, 2010). Além dos NASF, os programas de Residência Multiprofissional em Saúde da Família (RMSF) têm se destacado como portas de entrada para os psicólogos e outras profissões (geralmente as mesmas categorias dos NASF) no SUS. Tais espa- ços têm se tornado objeto de discussões, que buscam avaliar experiências e construir estratégias para atuação, nos espaços de gestão, atenção, formação e controle social (Conselho Federal de Psicologia, 2009, 2010; Iglesias, \& Avellar, 2016; Lancman et al., 2013; Macedo \& Dimenstein, 2011, 2012; Nepomuceno \& Brandão, 2011; Romagnoli, 2009; Spink, 2010).

É notável o papel ocupado pelas experiências de Residência Multiprofissional em Saúde (RMS), no que tange à formação profissional para o SUS. Tais experiências tomaram corpo, principalmente em meados de 1999, numa articulação de alguns atores sociais oriundos do movimento sanitário como Ministério da Saúde, motivados pela excelência reconhecida como "padrão ouro" de alguns dos modelos de formação em serviço já experimentados, principalmente pela medicina, que estabeleceram diretrizes iniciais para os modelos de RMS, incluindo reflexões sobre financiamento, credenciamento, validação e certificação (Brasil, 2006). As RMS expressam um movimento de resistência à hegemonia do paradigma biomédico e da ação política do complexo médico-industrial no campo da formação em saúde, o que tem gerado incômodo e polêmica entre os atores envolvidos (Dallegrave, \& Kruse, 2009). Tais experiências têm expressado o caráter contraditório do desenvolvimento do SUS, através de disputas que entram em cena no cotidiano das práticas em saúde. Aqui, as diversas categorias profissionais são colocadas num movimento de questionamento da especialização, da fragmentação do conhecimento e do biologicismo imperante no setor saúde, que advoga em favor da integralidade do cuidado, da ação intersetorial e da interdisciplinaridade. Nesse ínterim, em 2005, a Lei № 11.129 (Brasil, 2005) institui as residências multiprofissionais e em área profissional da saúde. E, em 2009, a portaria interministerial $\mathrm{n}^{\circ} 1.077$ (envolvendo ministérios da Saúde e da Educação) institui a Comissão Nacional de Residência Multiprofissional em Saúde,, entidade responsável para aglutinar os representantes legais oriundos do Ministério da Saúde e da Educação, das Instituições de Ensino, entidades de classe e controle social, autorizados a acompanhar, avaliar, credenciar e certificar os referidos programas. Ademais das controvérsias, contradições e opiniões contrárias, que a RMS vem despertando (Dallegrave, \& Kruse, 2009), advindas desse lugar de crítica e contra-hegemonia que alguns de seus atores vêm buscando ocupar, é destacável o caráter inovador de muitas das iniciativas proporcionadas nesse lócus 
de formação e produção de conhecimentos. Uma das áreas destinadas como foco de programas de RMS é a ESF. Os programas de RMSF vêm se ampliando no Brasil. No Ceará, a Psicologia participa desses programas desde 2001, através da Escola da Formação em Saúde da Família Visconde de Saboia, em Sobral. A criação do programa de RMSF em Fortaleza (em 2009) e sua posterior ampliação para outros municípios do Estado (em 2013), por meio das Residências Integradas em Saúde (coordenadas pela Escola de Saúde Pública do Ceará) resultou no aumento na participação dos psicólogos na ESF do SUS.

\section{Nuances do campo social: elementos teóricos}

A utilização do conceito de campo social, como concebido por Pierre Bourdieu, tem a intenção de abarcar, como objeto de análise, um universo da realidade social no qual estão inseridos agentes e instituições que produzem, reproduzem e divulgam um conjunto de práticas sociais específicas. Campo é definido como um espaço relativamente autônomo frente ao macrocosmo social, um microcosmo dotado particularidades. Essa relação entre macro e micro é, portanto, refletida numa permeabilidade variante entre campos, em que as fronteiras ora se apresentam mais bem estabelecidas e fechadas, ora se reconfiguram. O grau de autonomia que um campo ou subcampo social usufrui, a natureza das pressões externas e sua influência no meio interno revelam questões fundamentais para compreender o dinamismo de funcionamento do campo em sua relação com o contexto macrossocial (Bourdieu, 2004, 2012).

Tomando o caso do campo científico, como exemplo de campo social, podemos ver na reflexão bourdieusiana a intenção de operar uma tripla ruptura epistemológica: 1) ruptura com a ideia de ciência pura, própria da visão internalista que valoriza a dimensão microssocial e que relaciona a produção de ideias ao mundo específico da ciência e ou da história particular dos autores; 2) ruptura com a ideia de comunidade científica, numa visão homogeneizadora das práticas e da dinâmica científica; e 3) ruptura com a visão externalista, que sobrevaloriza o contexto socioeconômico como determinante das ideias e questões elegidas pela ciência (Bourdieu, 2008). Para o autor, quanto maior a autonomia de um campo específico, maior a capacidade de refratar as pressões e demandas externas. Estas serão transfiguradas e, por vezes, irreconhecíveis. Numa situação contrária, quando há uma grande heteronomia do campo, a permeabilidade às demandas e pressões externas é bastante significativa. Assim, todo campo é:

[...] um campo de forças e um campo de lutas para conservar ou transformar esse campo de forças. [...] É a estrutura das relações objetivas entre os agentes que determina o que eles podem e não podem fazer. $\mathrm{Ou}$, mais precisamente, é a posição que eles ocupam nessa estrutura que determina ou orienta [...] suas tomadas de posição (Bourdieu, 2004, p. 23).

Essa estrutura de relações objetivas entre os agentes comanda os pontos de vista mais reconhecidos, as intervenções, os lugares ocupados, as trajetórias possíveis, os limites da ação dos agentes. E tal estrutura é determinada pela distribuição do capital simbólico acumulado pelos agentes num dado momento. Aqui, novamente remetemo-nos à noção de campo científico em que "os agentes fazem os fatos científicos e até mesmo fazem, mas a partir de uma posição nesse campo" (Bourdieu, 2004, p. 25). O capital de crédito e a posição ocupada na estrutura de distribuição do capital influenciam as possibilidades e impossibilidades dos agentes submeterem o campo aos seus próprios desejos. O capital, aqui, é apresentado pelo autor como um tipo de capital simbólico, que é dado pelo reconhecimento ou crédito atribuído pelos pares-concorrentes no interior do campo, algo próximo ao prestígio ou a honra. O capital simbólico, embora se relacione com a ordem econômica e política da sociedade, não é o mesmo que o capital econômico. Cada campo tem sua especificidade e suas regras de funcionamento.

No presente estudo, utilizamos a noção de campo como forma de aprofundar nosso olhar para o processo de construção social das práticas profissionais no espaço da APS do SUS, trabalhando a ideia de que há um conjunto estruturado e estruturante de relações de poder que condicionam o desenvolvimento das práticas dos psicólogos e é por elas condicionado. Concebemos que esse campo é permeado por questões oriundas de campos como da Saúde Coletiva e das profissões inseridas na ESF. Assim, ao olhar para a APS do SUS, entendemo-la como um espaço social particular e relativamente autônomo, que sofre influência de diversos outros campos sociais ligados à estrutu- 
ração das políticas sociais e econômicas e a práticas vigentes em diversas disciplinas científicas e profissões de saúde. A utilização do referido conceito remete a conceber que a ação dos agentes é sempre permeada por atravessamentos sociais histórica e objetivamente estruturados a partir de relações de poder. Assim, busca-se a compreensão da ação, considerando aspectos situacionais, estruturais e simbólicos do espaço social. Há, portanto, o reconhecimento de que determinadas posições no espaço social constituem relações objetivas que, sob determinadas condições, tendem a se reproduzir de modo semelhante. Estudar o campo da ESF é voltar-se para compreender as relações de poder existentes no espaço de construção social das práticas de saúde nos CSF, analisando divisões de poder estruturantes, posições, relações, posicionamentos e estratégias adotadas por agentes e instituições.

\section{Método}

O presente trabalho é um estudo de abordagem qualitativa, voltado para a interpretação da experiência vivida por psicólogos na ESF, analisando a realidade social onde tais experiências são vividas, a partir do relato dos agentes. Baseamo-nos na ideia de que uma epistemologia qualitativa se apoia em três princípios, que são: conceber o conhecimento como uma produção construtivo-interpretativa; ter clareza que o processo de produção do conhecimento é de caráter interativo; e ter como nível legítimo da produção do conhecimento, a significação da singularidade, destacando a qualidade da expressão dos sujeitos estudados e não a quantidade destes (Gonzalez Rey, 2002).

Seguindo a intencionalidade epistemológica da pesquisa qualitativa, a construção das informações se deu através da realização de entrevistas junto a 18 psicólogos com experiência na formação e atenção à saúde na ESF. Para a escolha dos participantes, priorizamos entrevistar psicólogos inseridos em programas de RMSF em Fortaleza e Sobral, por reconhecer a importância desse dispositivo para a redefinição de referências para a atuação na ESF. A localização dos participantes ocorreu por meio de contatos com a Escola de Formação em Saúde da Família Visconde de Sabóia (em Sobral), a Escola de Saúde Pública do Ceará e a Prefeitura Municipal de Fortaleza. No decorrer do trabalho de campo, visando ampliar o diálogo com psicólogos inseridos na ESF de modos diversos, buscamos a participação de profissionais inseridos em NASF nos mesmos municípios e docentes de uni- versidades públicas. Para tal, entramos em contato com dois profissionais de NASF indicados por participantes já entrevistados e buscamos o contato com dois professores de cursos de Psicologia da Universidade Federal do Ceará e da Universidade Estadual do Ceará. No total realizamos 14 entrevistas individuais e duas entrevistas com duplas, totalizando 18 participantes, sendo 11 mulheres e sete homens. As entrevistas tiveram duração média de 60 minutos. A realização das entrevistas em duplas foi uma alternativa proposta pelos participantes diante de dificuldades de tempo livre e de oportunidades de encontro surgidas. Observamos que todas entrevistas foram ricas e proporcionaram interlocuções relevantes para os objetivos da pesquisa. Todos participantes assinaram o Termo de Consentimento Livre e Esclarecido e a pesquisa foi aprovada no Comitê de Ética em Pesquisa com o CAAE 01319712.0.0000.5051.

Quanto ao perfil dos participantes, em termos de tempo de trabalho na ESF, a maioria tinha mais de dois anos de experiência - somente dois participantes não tinham atingido o tempo 15 meses. Quanto à formação acadêmica, um participante já tinha concluído doutorado em Psicologia, cinco, já haviam concluído mestrado em Saúde Pública, três tinham mestrado em Saúde da Família e um, mestrado em Psicologia, outros dois estavam cursando mestrado em Saúde Pública, 13 já haviam concluído residência multiprofissonal em Saúde da Família (seis em Sobral e sete em Fortaleza). Quanto às experiências profissionais, 17 já tinham trabalhado como psicólogos da APS do SUS e sete dos entrevistados tiveram experiências profissionais de ensino em saúde direcionado para a atuação na ESF - sendo dois em cursos na graduação e cinco em programas de RMSF (três em Sobral e dois em Fortaleza). Pudemos observar que os participantes tinham vasta experiência no campo das práticas psicológicas na ESF.

A escolha por encerrar as entrevistas, delimitando o corte amostral de nosso estudo, se deu pela quantidade e riqueza semântica do material e sua relevância, para os objetivos propostos. Nesse ponto, nos orientamos pelo princípio da saturação teórica (Bauer, \& Aarts, 2004; Fontanella, Ricas, \& Turato, 2008), por meio do qual percebemos que a inclusão de novos participantes já estava se tornando pouco significativa para as reflexões teóricas que nos propusemos fazer, pela redundância ou repetição dos significados e representações percebida nas últimas entrevistas. 
Tomando algumas ideias de Paul Ricoeur (1989, 2009), buscamos colocar em prática, na análise do material produzido na pesquisa, a proposição de uma hermenêutica do texto como obra aberta a apropriações. Essa foi nossa postura interpretativa diante dos textos transcritos das entrevistas. Procedemos de modo a executar, várias vezes e de diversas formas, movimentos de análise e compreensão das entrevistas para a elaboração de uma interpretação pertinente ao contexto estudado. Primeiramente, partindo de um movimento de compreensão naive, ou ingênua, através do qual se conhece de modo superficial o todo dos textos das entrevistas, numa compreensão conjectural. Dessa "conjectura" inicial, partimos em um movimento mais aprofundado de compreensão, apoiado em processos analíticos das partes e relações entre as partes do texto, problematizando nossa perspectiva de interpretação. Nesse processo, no qual se busca uma espécie de "distanciação" visando à objetivação do texto, pode-se chegar ao que Ricoeur chama de "apropriação" (Ricoeur, 2009). O termo conjectura liga-se à ideia de que não é possível acessar a intenção do autor, que elaborou o texto. A passagem da conjectura à apropriação deve contemplar um processo de encadeamento de "um discurso novo no discurso do texto" (Ricoeur, 1989, p. 155), a partir de um exercício hermenêutico que entrelaça explicação e compreensão.

$\mathrm{Na}$ interpretação das entrevistas, primeiramente identificamos, como resultado da escuta das gravações e de leituras iniciais das transcrições das entrevistas, uma estrutura inicial de temas do material, que fez parte do que chamamos interpretação conjectural inicial. Com o intuito de aprimorar e agilizar a codificação dos textos das entrevistas e subsidiar o aprofundamento da análise das unidades de significação do material, utilizamos como ferramenta o software Atlas TI. O referido programa consiste em uma ferramenta para a análise de dados qualitativos que pode facilitar a codificação, categorização e interpretação de textos. Utilizamos o software de modo limitado à criação e identificação de unidades de significação pertinentes aos textos das 16 entrevistas, que compõem o material empírico da pesquisa. Interessou-nos, assim, a utilização do programa para a organização dos dados a partir da codificação e categorização das partes dos textos. Nesse processo, criamos 22 unidades de significação associadas a citações de partes das entrevistas (Nepomuceno, 2014). No presente trabalho, discutiremos as unidades de significação que nos possibilitam conhecer e analisar a ESF, como campo social, a partir da ótica dos participantes. São elas: características da APS, prerrogativas para a atuação profissional na ESF, desafios da APS, o processo de trabalho multiprofissional, hierarquia entre profissões no CSF, âmbitos da prática psicológica e os lugares ocupados pelo psicólogo no CSF.

\section{Resultados e Discussão}

Para contemplar os objetivos propostos, destacamos algumas características da ESF percebidas como marcantes para a construção das práticas psicológicas, sob ótica dos psicólogos. Nesse aspecto, elementos da dinâmica do campo serão descritos a partir de um conjunto de prerrogativas de atuação e características do processo de trabalho no referido espaço social. A análise dos lugares ocupados pelas práticas psicológicas na ESF nos ajudará a pensar potencialidades e limitações colocadas no cotidiano de trabalho à profissão. Destacaremos também contradições e ambivalências pertinentes ao reconhecimento e valorização da Psicologia dentro dos NASF e RMSF. Utilizando as unidades de significação construídas na interpretação das entrevistas, organizamos a apresentação de resultados e discussão em três tópicos: 1) Características do processo de trabalho na ESF: imperativos, potencialidades e desafios; 2) Hierarquias e divisões de poder; e 3) Posição da Psicologia na ESF.

\section{Características do processo de trabalho na ESF: demandas, potencialidades e desafios}

Como percebido pelos psicólogos participantes da pesquisa, a ESF se destaca por um tipo específico de demandas, no qual se revelam dimensões sociais do sofrimento humano. Desse modo, as práticas profissionais precisam orientar-se regularmente por uma leitura social dos problemas de saúde, que possibilite compreender o usuário do serviço em sua inserção no território/comunidade. Assim, o objeto das práticas nesse campo está diretamente ligado ao entrelaçamento entre contextos individuais e sociocomunitários. Nesse ponto, a ESF impõe a necessidade de territorialização das práticas, que implica no reconhecimento das condições de vida dos usuários, bem como na possibilidade de intervir nelas. Notamos, assim, um imperativo de reformulação de práticas profissionais para adequar-se ao contexto dinâmico de uma atuação na perspectiva social-comunitária, territorial.

O que fica mais pra mim, da atuação na atenção primária, é que a gente tem que construir essa atu- 
ação a partir das demandas e das necessidades do território. Porque elas vão dizendo o que a gente vai desenvolver [...] Tem que ser flexível mesmo a essa realidade, flexível, sensível (Participante 2).

O tema da territorialização foi recorrente nas falas dos participantes sobre o cotidiano das práticas profissionais nos CSF. Formal e informalmente a necessidade de territorializar a prática implica na imposição, pela própria forma como o campo tem se organizado, de certa necessidade de abertura a diversas áreas e abordagens técnico-científicas. Inserido nas diretrizes estabelecidas desde a criação da ESF, o termo "territorialização" é compreendido como "ferramenta metodológica que possibilita o reconhecimento das condições de vida e da situação de saúde da população de uma área de abrangência" (Monken et al., 2008, p. 246). Também pode ser considerada uma ferramenta para o planejamento das ações, enfatizando seu caráter de coleta/produção de dados para elaboração de diagnósticos de condições de vida e situação de saúde. Esse processo também torna relevante o estabelecimento de vínculos entre os profissionais e deles com os usuários-moradores do território comunidade, favorecendo a corresponsabilização pela saúde (Camargo-Borges, \& Cardoso, 2005; Oliveira, \& Furlan, 2008). No campo da ESF, portanto, as práticas psicológicas desenvolvem-se influenciadas pela dinâmica interação com uma complexidade de fatores socioculturais articulados.

Outro aspecto caracterizador da prática profissional na ESF é a necessidade de um trabalho de generalista. Como na frase de um participante: "quando a gente está na ESF, existe uma perspectiva de trabalho generalista, porque a gente tem que saber de tudo um pouco" (Participante 1). Esse trabalho de generalista é uma matriz de identidade profissional, que demarca a definição e a representação legítima das práticas em saúde nos CSF. Aqui, em certa medida, limitam-se os espaços para "especialismos" ou abordagens profissionais limitadas a áreas específicas do saber-fazer. Assim, a prática profissional é marcada por certo ecletismo teórico e metodológico, no qual as práticas profissionais são marcadas pela necessidade de articulação entre áreas de atuação e abordagens entre profissões e intraprofissões. Essa articulação entre áreas inter e intraprofissionais é percebida como uma prerrogativa para a atuação psicológica nos CSF. Assim, por exemplo, como relataram alguns participantes, para atender à demanda, é necessário tran- sitar entre diversas áreas do conhecimento, reconstruindo permanentemente as práticas nesse trânsito interteórico e intersetorial e negociando a construção de pontos de encontro e de produção de novos modos de agir e pensar.

Eu acho que a gente tem que tentar pensar um ponto de encontro em tudo. Porque não dá ser especialista em tudo, não dá pra eu ser especialista em Psicologia Escolar, especialista em Psicologia Social. [...] É a escola, é o social, é a saúde, é a saúde mental. Então, assim, nessa interseção de tudo, o que eu posso fazer? (Participante 5).

Um fazer de interseções demarca o modo de desenvolvimento de práticas interdisciplinares e ecléticas quando de suas interinfluências com diversas áreas de atuação das profissões inseridas na ESF. Essa interseção permanente das áreas de atuação e abordagens teóricas aponta para a complexidade inerente a uma dimensão epistemológica da produção das práticas, sempre impondo certa tensão atualizadora - um revisitar dos conceitos, teorias e técnicas mobilizadas no cotidiano. Como destaca um dos entrevistados, “[...] é necessário transcender as áreas, as caixinhas, porque na atenção primária são diversas as demandas. Porque, no fundo, o que temos ali é vida pulsante" (Participante 15). Nesse aspecto, destacamos o limite das teorias existentes pra ligar com os processos de trabalho, percebidos como "angustiante novidade" por vários dos participantes. O "ineditismo" se coloca como um desafio histórico de criação de práticas, que precisam ser sistematizadas e problematizadas nos níveis micro e macropolíticos. Em consonância com Lancman et al. (2013), que desenvolveram estudo sobre a dinâmica do trabalho nos NASF, os profissionais entrevistados relataram a preocupação com uma contraditória dinâmica de trabalho motivadora e estressante, na qual a invenção cotidiana do trabalho é permeada pela luta permanente pela constituição de um lugar, ainda impreciso e desconhecido, na produção das práticas na ESF. Assim, "tudo é motivador, mas, ao mesmo tempo, angustiante já que efetivamente é tudo muito inédito" (Participante 13). É louvável, nessa perspectiva, o investimento em reformulações curriculares e aproximações entre a universidade e os serviços de saúde, como apontam alguns estudos (Dimenstein, \& Macedo, 2012; Macedo, \& Dimenstein, 2011; Pitombeira et al., 2016), para a construção de novas referências para a Psicologia. 
Outra notável característica da ESF é o seu entrelaçamento com outros serviços de saúde. Assim, esse fazer de interface é também situado em rede de serviços articulando diversas políticas e programas de saúde. Pensar o campo, nesse sentido, é pensar no desafio de um fazer permeável, mas que precisa se colocar como específico, sistematizar e consolidar alguns referenciais técnico-científicos, para constituir posições e posicionamentos necessários diante de relações de poder e trocas existentes dentro do campo.

O espaço do CSF é marcado pela diversidade e intensidade de demandas oriundas de graves problemas de saúde da população, frente aos quais os profissionais têm de se posicionar de modo adequado na delimitação de práticas consequentes e efetivas. Em meio às pressões das demandas, as representações do que é ou deve ser a prática profissional nos espaços do CSF abrem espaços para intensas lutas entre os agentes inseridos no cotidiano dos serviços. Dentro de uma perspectiva bourdieusiana (Bourdieu, 2004, 2008, 2012), um campo constitui-se em um espaço social marcado por estruturas estruturantes específicas, que impõem limites e possibilidades para o desenvolvimento das práticas. Assim, entendemos o espaço social da ESF como aquele atravessado por lutas pela legitimação das práticas profissionais, no qual os agentes investem na busca por consolidar visões favoráveis à ampliação da autonomia profissional. O capital acumulado por agentes e instituições, que é fruto de um trabalho passado, define probabilidades de ganho a partir da posição ocupada no espaço. No que diz respeito ao capital simbólico, expresso no prestígio e reputação, podemos pensar as relações de lutas pelo poder de fazer, ver, crer e mesmo impor uma classificação legítima. Desse modo, são travadas disputas profissionais para definir o que é e o que não é legítimo de se fazer na ESF. No caso da Psicologia, o que é e o que não é papel do psicólogo, o que é e o que não é demanda para a Psicologia, qual a melhor forma de agir, quais as ações mais efetivas etc. Assim, o campo de práticas da ESF constitui uma arena onde lutas históricas das profissões se apresentam e também criam novos embates, que reverberam nos campos intra e interprofissionais. Desse modo, vivemos um momento fértil de possibilidades e entraves políticos e epistemológicos a superar. No que tange a preparação dos novos profissionais para inserir-se nesse contexto, é preciso consolidar algumas práticas e perspectivas teórico-metodológicas.

\section{Hierarquias e divisões de poder na ESF}

Seguindo na interpretação das entrevistas à luz da teoria dos campos sociais, de Bourdieu, podemos conceber a ESF sob o prisma do trabalho em equipe multiprofissional e pela divisão e classificação hierárquica das ações profissionais. No trabalho multiprofissional, destacam-se colaborações, articulações e disputas. Numa trama relacional, os profissionais apontam alguns pontos em comum, entre as disciplinas e as trajetórias de formação dos agentes, para estabelecer bases de comunicação e trocas voltadas para instaurar consensos satisfatórios em torno das práticas a realizar. No caso da prática dos psicólogos nas equipes multiprofissionais, alguns temas e questões foram identificados como facilitadores de diálogos e articulações profissionais. Esse diálogo com outras profissões remete a uma abertura pra conhecer, entender e negociar possibilidades de práticas colaborativas articulando múltiplos pontos de vista. A interpenetração de saberes e práticas no desenvolvimento do trabalho em equipe na ESF foi uma característica apontada por alguns dos entrevistados.

A disputa e a colaboração profissional na APS revelaram um terreno ambivalente e contraditório em que o trabalho em equipe é reconhecido como um fator de potencialização das práticas profissionais (pelo contributo interprofissional), mas também de tensão pela demarcação do melhor ponto de vista e objeto de intervenção. As dificuldades de articulação de ações entre equipes, especialmente das equipes de apoio (os NASF e RMSF) com as equipes mínimas, foram um desafio explicitado na análise do campo da ESF, pelos participantes. Como exemplo desse desafio citado, o exercício de práticas dentro da proposição de uma clínica compartilhada, expressa o modo como uma prerrogativa do campo, a do trabalho em equipe - entre equipes e serviços, remete a uma negociação permanente dos processos coletivos, que perpassam o trabalho de definição, execução e avaliação das práticas.

Essa história da gente fazer uma clínica com outras pessoas [...] tentando encaixar na rotina de trabalho de um médico, numa atuação conjunta. Um atendimento conjunto, tentando puxar o médico com a enfermeira da equipe mínima pra fazer uma atividade com a gente. A gente começava a mexer em questões do cotidiano de trabalho dessa galera e da própria forma do trabalho 
do CSF ser organizado. [...] Então, assim, se você trabalha conjuntamente, você mexe com o seu trabalho, mas mexe com o do outro também. E aí, isso é um desafio grande (Participante 8).

A organização de uma agenda de encontros entre categorias profissionais foi uma necessidade política relatada, para organização das práticas na APS, pelas interfaces estabelecidas nos processos de trabalho em equipe multiprofissional. As articulações eram necessárias para compartilhar os desafios cotidianos do trabalho e criar um espaço de participação coletiva para a problematização e definição das responsabilidades, alcances e limites das práticas profissionais. Era necessário “[...] sentar e conversar. Sentar e conversar sobre as visitas domiciliares, sobre os grupos, sobre o que queríamos fazer" (Participante 10). Nessa perspectiva, a constituição das práticas profissionais, dentro do espaço social dos CSF, requisita habilidades de negociação e de luta para impor pontos de vista favoráveis ao desenvolvimento das ações.

É importante destacar que as visões trazidas aqui são determinadas pelo lugar que os participantes ocupam no campo. Esse lugar é caracterizado por significados e sentidos construídos a partir do prisma de quem faz parte de uma equipe de apoio às equipes mínimas da ESF. Essa condição de equipe de apoio marca o tipo de fazer profissional e suas representações, bem como demarca a perspectiva de análise que desenvolvemos aqui. Falamos, assim, da perspectiva de um agente promotor de práticas voltadas, além de questões específicas da profissão, para responder demandas construídas pelo encaminhamento realizado pelas diversas equipes mínimas, já estruturadas na ESF, situadas nos territórios amplos em que os profissionais estiveram inseridos. Nesse contexto, é importante destacar a prerrogativa estabelecida pelas diretrizes da ESF, nos planos macro e micropolíticos, de que os psicólogos, como membros de equipes multiprofissionais de NASF e RMSF, não deveriam ser porta de entrada para a APS - o que implica numa relação de condicionalidade das práticas das equipes de apoio. O fazer psicológico, assim, é amarrado às demandas de outras categorias profissionais, especialmente as já consolidadas da equipe mínima da ESF. Essa condição de equipe de apoio será uma demarcação fundamental para a classificação hierárquica das ações profissionais nos CSF.
As percepções sobre a ESF nos levam a identificar que a hegemonia da medicina e do modelo biomédico marca a organização e classificação das práticas em saúde nos CSF. As relações, assim, são percebidas como hierarquizadas e o lugar do psicólogo é subalternizado frente ao poder ensejado pelas práticas médicas. Barros (2002) desenvolve uma análise do modelo biomédico e sua limitação e pertinência no processo saúde-doença, que é bastante útil a nossas pretensões de analisar o espaço social da APS do SUS. Segundo o autor, a constituição desse modelo explicativo e de intervenção em saúde decorre de um longo processo histórico de raízes na renascença e perpassa a construção do método científico moderno de produção de conhecimento sobre o corpo humano, as doenças, suas manifestações e cura-tratamento. Todo esse processo histórico e social remete à própria construção social da medicina como ciência e profissão socialmente reconhecida. A legitimação social da medicina implica direta e indiretamente na crescente medicalização da sociedade que, por sua vez, é também fruto do desenvolvimento do capitalismo, da mercantilização da saúde (Barros, 2002). Na presente pesquisa, pudemos evidenciar a hegemonia da categoria médica na constituição do espaço de práticas na ESF, o que reverbera no prestígio e reputação adquiridos pelas práticas pautadas no modelo biomédico. A análise da experiência dos participantes da pesquisa nos dá subsídio para a constatação de que as desigualdades de poder e estratégias de dominação atravessam as práticas do campo e tem como modelo biomédico como hegemônico. Dentro de uma espécie de hierarquia das profissões, o modelo biomédico é um estruturador das trocas simbólicas e elemento de referência na regulação das classificações e valorações das práticas.

Eu tenho a impressão que ainda tem uma hierarquia regulada por essa hegemonia da medicina, enquanto a profissão de ponta ainda desses espaços. Muito embora o campo tenha se constituído a partir de uma crítica a essa hegemonia, eu acho que ele não conseguiu ainda se livrar dela (Participante 3).

A percepção da hierarquia médica na ESF corrobora com a hegemonia da medicina no plano sociocultural, já discutido em estudos clássicos (Illich, 1975; Nogueira, 2003) e focados na perspectiva da desme- 
dicalização nos serviços de saúde (Romagnoli, 2009; Tesser, Poli Neto, \& Campos, 2010). Essa hierarquização marca o processo de trabalho da ESF com um conjunto de privilégios e regalias da categoria médica na organização de uma agenda de trabalho e de favorecimentos quando da definição das condições de trabalho e contratação. A hierarquização do processo de trabalho produz sofrimento aos demais profissionais e trabalhadores, pela não autorização de algumas práticas, que ficam subalternizadas frente ao controle imposto pelo modelo biomédico. Um dos exemplos, trazidos nas entrevistas, é o poder do encaminhamento médico, como evidência do domínio desse especialista no desenvolvimento e legitimação das práticas. Percebemos certa centralização do poder de encaminhar casos para outros profissionais, especialmente para os de outras especialidades médicas, que implica na desautorização de outros agentes envolvidos na construção de algumas práticas. "Por exemplo, uma criança só pode chegar por encaminhamento para o psicólogo via o parecer do médico. O paciente que vai encaminhado pro CAPS ele também precisa do parecer do clínico, do médico, pra poder esse encaminhamento se efetivar" (Participante 3). A desautorização das práticas não médicas é uma característica do processo de trabalho multiprofissional da ESF, percebida pelos psicólogos. O poder médico impõe-se na definição de uma dinâmica de relações profissionais e entre serviços, cujo ritmo e perspectivas das práticas estão sob o controle quase exclusivo dos médicos. Nesse contexto, a prática psicológica é relativamente inferiorizada e sua dinâmica é afetada pelo domínio imposto pela hegemonia do modelo biomédico. A sua estrutura hierarquizada da ESF corrobora para a desvalorização da ESF como espaço profissional de atuação para os psicólogos entrevistados. O domínio médico é constituído de diversos modos e demarcações de poder, que se estruturam no cotidiano percebido das relações de trabalho.

Eu acho que tem algumas demarcações de poder. Por exemplo, a gente está lidando com quem, na equipe mínima? É com médico, enfermeira e o agente comunitário de saúde. A gente percebe que o médico tem uma flexibilidade pra produzir o horário dele do jeito que ele quiser. Então, assim, tem médico que diz "olhe, quinta-feira tenho plantão no hospital e eu não trabalho”. E o cara não trabalha. É contratado para quarenta horas, de segunda a sexta, mas quinta-feira ele não trabalha. Ele definiu isso. Ou então o cara diz assim: "não, eu atendo tantos pacientes por dia e terminando esses pacientes eu vou embora", o cara atende rápido e pode tipo, dez horas, ele ter terminado. Ou até assim, isso não acontecia no meu CSF, mas eu sabia de CSF que era assim: o cara chegava seis e meia, sete horas e dava nove, ele já tinha atendido uma galera e ia embora. E aí, assim, todo o resto das coisas do CSF acontecendo ali naquele turno. Mas ele tinha terminado a prática dele, né! Então assim, quem é que consegue fazer isso? Quem é que tem essa autoridade pra dizer "eu trabalho assim e ponto final?" (Participante 8).

O poder simbólico dos médicos para definir o melhor modo de organização das práticas de forma arbitrária é uma das marcas do processo de trabalho em equipe da ESF. Dentre os problemas decorrentes de usos e abusos do poder médico, que marcam o cotidiano na ESF, os participantes percebem que o sistema de saúde é, geralmente, colocado como refém dos interesses médicos, que conseguem legitimar um lugar privilegiado nas relações construídas no campo. Percebe-se que a ESF tem sofrido influência marcante de agentes e instituições médicas. Tal fato revela contradições e obstáculos a APS do SUS, especialmente no que diz respeito a sua proposta desmedicalizadora. Romagnoli (2009), em estudo sobre as práticas da ESF em Betim (Minas Gerais), destaca a hegemonia da medicina na constituição do modelo assistencial desenvolvido, o qual apresenta fragilidades no conhecimento do território e das necessidades de saúde da população. A autora identifica como problemas da ESF, a ênfase preponderante nas práticas centradas na terapêutica medicamentosa, a pouca articulação das redes de atenção em saúde mental e a dificuldade de se trabalhar com grupos. Para Romagnoli, o processo de institucionalização das práticas, é marcado pela prevalência de relações hierarquizadas de saberes e poderes, em que se percebe a hegemonia do modelo biomédico e da frequente medicalização do sofrimento.

A partir de nossas entrevistas, ficou-nos evidente que as desigualdades de poder demarcaram as trajetórias dos participantes nos CSF. Tais desigualdades foram identificadas destacadamente nas diferenciações de poder existentes entre equipes mínimas e equipes de apoio. Nessa visão do campo, as novas profissões, que integram a ESF, ocupam uma posição complementar 
e inferior, especialmente, no que diz respeito à hegemonia dos saberes e práticas construídos na perspectiva do modelo biomédico. A partir das experiências analisadas, percebemos que grandes desigualdades de poder entre equipes mínimas e NASF/RMSF operam no processo de definição e desenvolvimento das práticas no cotidiano dos CSF, no qual a prática de um profissional de NASF/RMSF está condicionada ao trabalho desenvolvido nas equipes mínimas.

\section{Posição da Psicologia na ESF}

A posição ocupada pela profissão na ESF é bastante condicionada pelo modo suas práticas se inserem nos CSF e seus territórios. No contexto de nossos entrevistados, o processo de trabalho é bastante marcado pela divisão de poder instaurada entre equipes mínimas e equipes de apoio.

Digamos que o Saúde da Família é a casa da medicina de título, de propriedade, mas quem governa é a enfermagem [...] os Agentes Comunitários de Saúde são os empregados fixos da casa - e bastante explorados de todas as formas. As outras profissões, inclusive a Psicologia, são os convidados "pra consertar TV a cabo" - os técnicos que vem e são chamados pra algum tipo de serviço. Nós somos esse outro rol de profissões, das profissões que ainda atuam sobre a lógica a prestação de serviço, pelo entendimento de quem solicita (Participante 7).

$\mathrm{O}$ pertencimento às equipes de apoio de NASF e RMSF, ademais do ressentimento que pode despertar pela referida subalternidade, não indica uma convivência igualitária e equilibrada entre as categorias profissionais dentro das equipes multiprofissionais de apoio. Há também diferenciações de poder entre os profissionais. A prática dos psicólogos, nesse contexto, é relativamente bem valorizada. Como relatam os participantes, o psicólogo é um agente especializado que ocupa um lugar privilegiado dentro do grupo de profissionais de apoio, pois possui um saber específico e um modo de agir peculiar fruto de processos de aprendizagem e formação: trabalha com questões subjetivas do processo saúde-doença-cuidado e é identificado como profissional de referência em saúde mental. Como destaca um dos entrevistados: "eu acho que nesse grupão no NASF, nós estamos bem por conta de lidar com muitas questões de saúde mental, as quais boa parte dos profissionais não está acostumada a lidar". O reconhecimento da distinta posição da Psicologia dentro dos NASF tem um significado ambivalente. Essa ambivalência decorre do fato de seu reconhecimento e valorização ser oriundo de visões limitadas sobre o que é a prática psicológica, originando um expressivo conjunto de demandas, que impõem desafios intransponíveis aos profissionais.

Os resultados da pesquisa nos permitem destacar a influência de uma contraditória visão hegemônica sobre a prática psicológica, permeada pelo imaginário social construído em torno da clínica psicológica em consultório particular. A visão que identifica o profissional psicólogo como um clínico, está impregnada no cotidiano da ESF. Essa visão, por um lado, aproxima a Psicologia de outras categorias, como a médica, e a diferencia de outras como a dos profissionais de Educação Física, pouco reconhecidos no espaço das práticas clínicas. O consultório psicológico, nesse imaginário social, é um elemento marcante na representação social típica da Psicologia. Saber lidar com as expectativas sociais em torno da profissão e criar alternativas às demandas, ampliando o reconhecimento sobre as possibilidades práticas psicológicas, foi um desafio para os participantes do estudo. Em geral, percebemos que muitos agentes inseridos na ESF veem, no psicólogo, um profissional que contribui significativamente para a resolução dos problemas de saúde trabalhados na ESF. Esse reconhecimento indica, ambiguamente, que há certa relevância social adquirida pelo profissional psicólogo na produção de práticas de APS, mas também, que as práticas psicológicas sofrem pressão de mecanismos de reprodução social de prática, dentro de um imaginário da profissão estereotipado. Nessa perspectiva, as demandas para a Psicologia têm significados ambivalentes no contexto das lutas entre as profissões nos CSF. Uma forte demanda e procura por psicólogos pode expressar o reconhecimento do valor significativo da prática psicológica. Mas, contraditoriamente, pode significar sua desvalorização, a partir da aceitação de demandas inadequadas frente ao que compete à Psicologia e que pode contribuir para a reprodução de uma prática profissional limitada.

Aspecto importante do processo de produção das práticas psicológicas nos CSF é que, em muitas de suas abordagens teórico-metodológicas, esse fazer obedece a lógicas diversas da lógica do modelo biomédico. Tais práticas voltam-se para objetos especí- 
ficos mais próximos da dimensão subjetiva e afetiva do processo saúde-doença-cuidado, o que difere da lógica das práticas centradas nos fatores biológicos. Esse caráter distinto das práticas psicológicas possibilita a demarcação de espaços de produção em que há mais autonomia profissional, estabelecida pelo domínio de códigos próprios que garantem a legitimação classificatória das ações (Dubar, 2005). É no vazio deixado pelo modelo biomédico, que a Psicologia se ressalta como profissão de referência para as práticas na ESF. Esse tema é apontado em várias entrevistas, e se expressa no reconhecimento de que a Psicologia "tem uma espécie de caixa-preta, tem certo funcionamento que só ela entende [...] então, acaba tendo uma relação menos hierárquica nesse sentido" (Participante 2). Ocupando esse espaço de alteridade, a Psicologia goza de certa autonomia relativa para gerir seus processos de trabalho que lhe garante um espaço diferencial na hierarquia do campo da APS. A busca da autonomia nas práticas profissionais está intimamente ligada à especialização técnica e a determinação de critérios de excelência (Machado, 1995), bem como a propriedade ou controle dos meios de produção (Durand, 1975). Percebemos que a profissão tem relativa autonomia na ESF pela demarcação de um conjunto de saberes específicos legitimados como próprios da Psicologia.

Ademais do lugar de relativo destaque ocupado dentro das equipes de apoio de NASF/RMSF, a posição da categoria profissional é ainda subalterna, como discutido acima. Esse lugar de menos-valia na economia das trocas simbólicas do CSF e da estruturação dos cargos efetivos dentro da ESF foi relatado pelos participantes da pesquisa. De um modo geral, identificamos alguns fatores responsáveis pelo desprestígio do trabalho no NASF e RMSF: a tensão imposta pelas relações de encaminhamento entre equipes mínimas e equipes de apoio; a hierarquia médica legitimada na classificação das prioridades; e as precárias condições de trabalho. A precarização das condições de trabalho no campo foi algo bastante presente dos diálogos realizados nas entrevistas. Sempre que esse tema surgiu nas entrevistas, os participantes expressavam certo pesar, já que muitos já viam, no período das entrevistas, a experiência da APS como passado de suas trajetórias profissionais. A ESF, assim, para a maioria dos participantes da pesquisa, não lhes apresentou perspectivas interessantes de construir de uma carreira no SUS.

\section{Considerações finais}

Em síntese, podemos compreender o campo da ESF como uma rede de agentes e instituições interconectados com a realidade sociocultural e modo de vida de usuários e trabalhadores de saúde. Nessa rede, as relações socioprofissionais são permeadas pela luta por autonomia na definição e classificação das práticas, visando a qualificação e consolidação de espaços para a atuação. A tradição biomédica se destaca como modelo assistencial de referência, influindo no processo de produção das práticas multiprofissionais e constituindo uma hierarquia médica nos CSF. O fazer profissional dos psicólogos, assim como para outros profissionais de NASF e RMSF, é marcado por interfaces, colaborações, negociações e conflitos, como parte da luta por legitimação. Ressalta-se a imagem de que os CSF são espaços de práticas profissionais, atravessados por difíceis desigualdades de poder, mas paradoxalmente abertos a diversas perspectivas de atuação, possibilitando o desenvolvimento de ações inovadoras em diversos âmbitos. No intuito de lograr os objetivos propostos, de compreender a ESF enquanto campo social e analisar os lugares ocupados pela Psicologia nesse contexto, nos deparamos com as características de um processo de trabalho marcado pela ambiguidade das relações sociais e pelos conflitos. Destacamos, nesse ínterim, a tensa e decisiva relação entre equipes mínimas e equipes de apoio, configurando importantes divisões de poder, que impõem restrições às práticas profissionais e delimitam enormes desafios de atuação e formação no plano do trabalho em equipes multiprofissionais e da rede de serviços.

Os psicólogos, assim como outros profissionais ingressantes nos CSF, sofrem pressões permanentes para definir e consolidar uma prática legitimada e reconhecida. Ressalta-se, aqui, a dimensão política do fazer profissional, expressa na capacidade de diálogo, interação e convencimento. Inserida na ESF, a Psicologia destaca-se, especialmente, ao atuar em certos "lugares vazios" deixados pelas demais profissões e pelo modelo biomédico, voltando-se para o acompanhamento de dimensões do sofrimento humano, que são mal acolhidas tradicionalmente pelos serviços de saúde. Como as experiências dos participantes nos revelam, o agir profissional da Psicologia é potente de reconhecimento e valorização. É urgente, nesse processo, a ação de agentes e instituições na elaboração de posicionamentos da profissão diante do campo, a partir da sistematização das práticas e contextualização de seus referenciais técnico-científicos. 


\section{Referências}

Andrade, L. O. M., Barreto, I. C. H.C., \& Bezerra, R. C. (2006). Atenção Primária à Saúde e Estratégia de Saúde da Família. In G. W. S. Campos, M. C. S.Minayo, M. Akerman, M. Drumond Júnior, \& Y. M. Carvalho (Orgs.). Tratado de saúde coletiva (pp. 783-836). São Paulo, SP: Hucitec.

Bauer, M. W., Aarts, B. (2004). A construção do corpus: um princípio para a coleta de dados qualitativos. In M. W. Bauer, \& G. Gaskell, Pesquisa qualitativa com texto, imagem e som: um manual prático (3a ed., 39-63). Petrópolis, RJ: Vozes.

Barros, J. A. C. (2002). Pensando o processo saúde doença: a que responde o modelo biomédico? Saúde e Sociedade, 11(1), 67-84. http://dx.doi.org/10.1590/S0104-12902002000100008

Bourdieu, P. (2011). Economia das trocas simbólicas. (7a ed.). São Paulo, SP: Perspectiva.

Bourdieu, P (2004). Os usos sociais da ciência: por uma sociologia clínica do campo científico. São Paulo, SP: Editora UNESP.

Bourdieu, P. (2008). Para uma sociologia da ciência. Lisboa: Edições 70.

Bourdieu, P. (2012). Poder simbólico (16a ed.). Rio de Janeiro: Bertrand Brasil.

Brasil. (2005, 1 de julho). Lei No 11.129, de 30 de junho de 2005. Institui o Programa Nacional de Inclusão de Jovens - ProJovem; cria o Conselho Nacional da Juventude - CNJ e a Secretaria Nacional de Juventude; altera as Leis nos 10.683, de 28 de maio de 2003, e 10.429, de 24 de abril de 2002; e dá outras providências. Diário Oficial da União.

Brasil. (2006). Ministério da Saúde. Secretaria de Gestão do Trabalho e da Educação na Saúde. Residência multiprofissional em saúde: experiências, avanços e desafios. Brasília, DF: Ministério da Saúde.

Brasil. (2008). Ministério da Saúde. Portaria GM No 154, de 24 de janeiro de 2008. Cria os Núcleos de Apoio à Saúde da Família - NASF. Recuperado de http://dab.saude.gov.br/docs/legislacao/portaria154_24_01_08.pdf

Brasil. (1997). Ministério da Saúde. Saúde da família: uma estratégia para a reorientação do modelo assistencial. Brasília, DF: Ministério da Saúde.

Camargo-Borges, C., \& Cardoso, C. L. (2005). A psicologia e a estratégia saúde da família: compondo saberes e fazeres. Psicologia \& Sociedade, 17(2), 26-32. http:// dx.doi.org/10.1590/S0102-71822005000200005

Conselho Federal de Psicologia. (2009). A prática da psicologia e o núcleo de apoio à saúde da família. Brasília, DF: Conselho Federal de Psicologia.

Conselho Federal de Psicologia. (2010). Práticas profissionais de psicólogos e psicólogas na atenção básica. Brasília, DF: Conselho Federal de Psicologia.

Dallegrave, D., \& Kruse, M. H. L. (2009). No olho do furacão, na ilha da fantasia: a invenção da residência multiprofissional em saúde. Interface (Botucatu), 13(28), 213-237. http://dx.doi.org/10.1590/S1414-32832009000100018

Dimenstein, M., \&Macedo,J.P. (2012).Formaçãoempsicologia:requisitosparaaatuaçãoematençãoprimáriaepsicossocial.Psicologia:CiênciaeProfissão,32(num.esp.),232-245.http://dx.doi.org/10.1590/S1414-98932012000500017

Dubar, C. (2005). A socialização: construção de identidades sociais e profissionais. São Paulo, SP: Martins Fontes.

Durand, J. C. G. (1975). A serviço da coletividade: crítica à sociologia das profissões. Revista de Administração Pública, 15(6), 59-69. http://dx.doi.org/10.1590/S0034-75901975000600005

Fontanella, B. J.B., Ricas, J., \&Turato, E. R. (2008). Amostragem por saturação em pesquisas qualitativas em saúde: contribuições teóricas. CadernosdeSaúdePública, 24(1),17-27.http://dx.doi.org/10.1590/S0102-311X2008000100003

Gonzalez Rey, F. (2002). Pesquisa qualitativa em psicologia: caminhos e desafios. São Paulo, SP: Pioneira Thompson Learning.

Iglesias, A., \& Avellar, L. Z. (2016). As contribuições dos psicólogos para o matriciamento em saúde mental. Psicologia: Ciência e Profissão, 36(2), 364-379. http://dx.doi.org/10.1590/1982-3703001372014

Illich, I. (1975). A expropriação da saúde: nêmesis da medicina. Rio de Janeiro, RJ: Nova Fronteira.

Lancman, S., Gonçalves, R. M. A., Cordone, N. G., \& Barros, J. O. (2013). Estudo do trabalho e do trabalhar no Núcleo de Apoio à Saúde da Família. Revista de Saúde Pública, 47(5), 968-75. 
Macedo, J. P., \& Dimenstein, M.. (2011). Expansão e interiorização da psicologia: reorganização dos saberes e poderes na atualidade. Psicologia: Ciência e Profissão, 31(2), 296-313. Recuperado de http://www.scielo.br/pdf/pcp/ v31n2/v31n2a08.pdf

Macedo, J. P., \& Dimenstein, M. (2012). O trabalho dos psicólogos nas políticas sociais no Brasil. Avances en Psicología Latinoamericana, 30(1), 182-192.

Machado, M. H. (1995). Sociologia das profissões: uma contribuição ao debate teórico. In M. H. Machado (Org.), Profissões de saúde: uma abordagem sociológica. Rio de Janeiro, RJ: Editora Fiocruz.

Monken, M., Peiter, P., Barcellos, C., Iñiguez Rojas, L., Navarro, M. B. M. A., Gondim, G. M. M. et al. (2008). O território na saúde. In A C Miranda, C. Barcellos, J. C. Moreira, \& M. Monken (Orgs.), Território, ambiente e saúde. Rio de Janeiro, RJ: Editora Fiocruz.

Nepomuceno, L. B. (2014). A construção social da prática psicológica na atenção primária à saúde do SUS (tese de doutorado). Universidade Federal do Ceará, Fortaleza, CE.

Nepomuceno, L. B., \& Brandão, I. R. (2011). Psicólogos na estratégia saúde da família: caminhos percorridos e desafios a superar. Psicologia:Ciênciae Profissão, 31(4),762-777.http://dx.doi.org/10.1590/S1414-98932011000400008

Nogueira, R. P. (2003). A saúde pelo avesso. Natal, RN: Seminare.

Oliveira, G. N., \& Furlan, P. G. (2008). Co-produção de projetos coletivos e diferentes "olhares" sobre o território. In G. W. S. Campos, \& A. V. P. Guerreiro (Orgss). Manual de práticas de atenção básica: saúde ampliada e compartilhada. São Paulo, SP: Aderaldo \& Rothschild.

Pitombeira, D. F., Xavier, A. S., Barroso, R. E. C., \& Oliveira, P. R. S. (2016). Psicologia e a formação para a saúde: experiências formativas e transformações curriculares em debate. Psicologia: Ciência e Profissão,36(2): 280-291. http://dx.doi.org/10.1590/1982-3703001722014

Ricoeur, P. (1989). Do texto à acção: ensaio de hermenêutica II. Porto: Rés-Editora.

Ricoeur, P. (2009). Teoria da interpretação: o discurso e o excesso de significação (A. Morão, trad.). Lisboa: Edições 70.

Romagnoli, R. C. (2009). Breve estudo institucionalista acerca do Programa de Saúde da Família. Saúde e Sociedade, 18(3), 525-536. http://dx.doi.org/10.1590/S0104-12902009000300016

Spink, M. J. (Org.). (2010). A psicologia em diálogo com o SUS: prática profissional e produção acadêmica. São Paulo, SP: Casa do Psicólogo.

Tesser, C. D., Poli Neto, P., \& Campos, G. W. S. (2010). Acolhimento e (des)medicalização social: um desafio para as equipes de saúde da família. Ciência \& Saúde Coletiva, 15(Supl. 3), 3615-3624. http://dx.doi.org/10.1590/S1413-81232010000900036

\section{Léo Barbosa Nepomuceno}

Doutor em Saúde Coletiva (UFC). Mestre em Psicologia (UFC). Especialista com Residência Multiprofissional em Saúde da Família (UVA). Professor Adjunto do Instituto de Educação Física e Esportes da Universidade Federal do Ceará, Fortaleza - CE, Brasil.

E-mail: leobnepomuceno@hotmail.com

\section{Ricardo José Soares Pontes}

Médico Sanitarista e Epidemiologista. Pós-Doutorado (Escola de Saúde Pública de Harvard). Doutor em Medicina Preventiva (USP). Professor Associado do Departamento de Saúde Comunitária, Programa de Pós Graduação em Saúde Coletiva, Faculdade de Medicina da Universidade Federal do Ceará, Fortaleza - CE, Brasil.

E-mail: rjpontes@fortalnet.com.br

Endereço para envio de correspondência:

Universidade Federal do Ceará, Faculdade de Medicina, Departamento de Saúde Comunitária.

Rua Professor Costa Mendes, 1608, 5º andar. Rodolfo Teófilo. CEP: 60430-140.

Fortaleza-CE, Brasil 
Recebido 10/02/2015

Reformulação 09/08/2016

Aprovado 10/02/2017

Received $02 / 10 / 2015$

Reformulated $08 / 09 / 2016$

Approved 02/10/2017

Recebido 10/02/2015

Reformulado 09/08/2016

Aceptado 10/02/2017

Como citar: Nepomuceno, L. B., \& Pontes, R. J. S. (2017). O espaço socioprofissional da Estratégia Saúde da Família sob a perspectiva de psicólogos. Psicologia: Ciência e Profissão, 37(2), 289-303. https://doi.org/10.1590/1982-370300352015

How to cite: Nepomuceno, L. B., \& Pontes, R. J. S. (2017). The social-professional space of the Family Health Strategy from the perspective of psychologists. Psicologia: Ciência e Profissão, 37(2), 289-303. https://doi.org/10.1590/1982-370300352015

Cómo citar: Nepomuceno, L. B., \& Pontes, R. J. S. (2017). El espacio social de la Estrategia Salud de la Familia bajo la perspectiva de psicólogos. Psicologia: Ciência e Profissão, 37(2), 289-303. https://doi.org/10.1590/1982-370300352015 